\title{
Essential drugs production in Brazil, Russia, India, China and South Africa (BRICS): opportunities and challenges
}

\author{
Zoheir Ezziane $e^{1,2 *}$ \\ Abstract \\ The objective of this work is to elucidate various essential drugs in the Brazil, Russia, India, China and South \\ Africa (BRICS) countries. It discusses the opportunities and challenges of the existing biotech infrastructure \\ and the production of drugs and vaccines in member states of the BRICS. This research is based on a systematic \\ literature review between the years 2000 and 2014 of documents retrieved from the databases Embase, PubMed/ \\ Medline, Global Health, and Google Scholar, and the websites of relevant international organizations, research \\ institutions and philanthropic organizations. Findings vary from one member state to another. These include useful \\ comparison between the BRICS countries in terms of pharmaceuticals expenditure versus total health expenditure, \\ local manufacturing of drugs/vaccines using technology and know-how transferred from developed countries, and \\ biotech entrepreneurial collaborations under the umbrella of the BRICS region. This study concludes by providing \\ recommendations to support more of inter collaborations among the BRICS countries as well as between BRICS and \\ many developing countries to shrink drug production costs. In addition, this collaboration would also culminate \\ in reaching out to poor countries that are not able to provide their communities and patients with cost-effective \\ essential medicines. \\ Keywords: Brazil, Russia, India, China, South Africa (BRICS); Global Health; Influence; Newly Emerging Economies \\ Copyright: @ 2014 by Kerman University of Medical Sciences \\ Citation: Ezziane Z. Essential drugs production in Brazil, Russia, India, China and South Africa (BRICS): \\ opportunities and challenges. Int J Health Policy Manag 2014; 3: 365-370. doi: 10.15171/ijhpm.2014.118
}

\section{Article History:}

Received: 11 July 2014 Accepted: 2 November 2014 ePublished: 6 November 2014

\footnotetext{
${ }^{*}$ Correspondence to:

Zoheir Ezziane

Email: zezziane@hct.ac.ae
}

\section{Introduction}

Since 2010, five newly emerging economies collectively known as 'BRICS' (Brazil, India, Russia, China and South Africa) have caught the imagination, and scholarly attention, of political scientists, economists and development specialists. The prospect of a unified geopolitical bloc, consciously seeking to reframe international (and global) health development with a new set of ideas and values, has also, if belatedly, begun to attract the attention of the global health community (1-4). But what influence, if any, do the BRICS wield in global health, and, if they do wield influence, how has that influence been conceptualized and recorded in the literature?

The total population of the BRICS is estimated in 2013 at 3 billion people with a combined nominal GDP of 14.8 trillion US dollars (5). These fast-growing economies and all G20 members exert considerable influence on regional and global affairs. However, the BRICS are currently encountering important domestic health challenges. These countries announced in many meetings their commitments to increasingly engage in global health. During the 2011 Ministers of Health meeting, the BRICS clearly indicated the potential benefits of collaboration and ultimately decided to tackle together common health challenges (6).

In a recent study, the BRICS bloc claims to constitute a paradigm shift in global health development from international relations framework which differentiates between material capabilities, institutions and ideas in order to compare different historical structures or 'frameworks for action' (7). This study infers some sort of skepticism in the context of global health a sense that collectively, the
BRICS countries focus more rhetoric rather than practice. However, these countries have implemented a progressive approach to global health when considering support for Research and Development (R\&D) into new drugs, products and technologies; and response to Non-Communicable Diseases (NCDs).

An empirical analysis illustrates how and why the BRICS summit system has governed global health. Essentially, the BRICS bloc is fully committed to its health-related commitments by creating the BRICS health ministers' institution and engaging with other multilateral institutions. In addition, and due to the lack of any significant leadership from the G8 and G20, the BRICS countries are leading the world among global plurilateral summit institutions in governing NCDs (8).

For over 35 years, the World health Organization (WHO) has launched the concept of essential medicines. Updated versions are released every two years since 1977. The current versions are the $18^{\text {th }}$ WHO Essential Medicines List for Adults and the $4^{\text {th }}$ WHO Essential Medicines List for Children updated in April 2013. As of 2011, the WHO Model List included 350 Essential Medicines [Essential Drug List (EDR)] and the National EDL of India list included 348 (9). In China, the 2004 list includes 1260 Chinese herbal preparations and 773 chemical and biological medicines products (10).

While many developing countries have been engaged in manufacturing relatively cost-effective drugs, the cooperation between BRICS and developing countries is leading towards distribution of lower-cost drugs compared to developed markets (11). For example, Brazil and Cuba are collaborating 
to produce meningitis A vaccine for Africa (12). In addition, Bio-Manguinhos (Brazil) and the Finlay Institute (Cuba) were found to be the most suitable suppliers of a meningitis vaccine by the WHO when both institutions collaborated during the outbreak of meningitis in 2007 and neither company alone could have conducted the job effectively. Moreover, Brazil is involved in building pharmaceutical plants in Africa and more specifically in Mozambique and Namibia to manufacture generic anti-retroviral medicines. Brazil also pledged 80 million US dollars to rebuild the health system in Haiti after the 2010 catastrophic earthquake (13). This paper explores the collaborations among the BRICS countries as well as between the BRICS and developing countries to shrink drug production costs.

The Indian firm Biological E is collaborating with the International Centre for Diarrhoeal Disease Research (ICDDR; Bangladesh) and co-developed a vaccine candidate to prevent cholera as this disease is very common in Bangladesh and eastern India. The two firms agreed that once this candidate proves to be effective and safe, Biological E would go ahead in manufacturing the vaccine (13).

China and Egypt also teamed in an entrepreneurial collaboration where production of recombinant insulin takes place in Egypt using technology from China. Hence, a local source of insulin was made available in Egypt and conveniently cheaper than the imported product (14).

In July 2014, the BRICS countries met and discussed their commitment to create a joint funding where health is a priority area to be supported and ensure that innovation is both accessible and affordable to those in need. Innovation in healthcare is witnessing many shortcomings including for example Tuberculosis (TB) which suffers from chronic under-investment due to a less attractive commercial market mainly in poor countries. A greater support for innovative mechanisms are needed to minimize the gaps in health and medical research especially the ones that promote collaboration and ensure sustainable funding to tackle diseases in poor and developing countries (15).

The entire world health community is watching very closely the innovative public health programs and policies undertaken by the BRICS countries. Their main contributions to global health include genetic drugs to manage HIV and TB as well as providing diverse health service delivery and innovative diagnostic tools (16).

This study helps to identify opportunities in drug production in inter-collaborations among BRICS, as wells as BRICS and developing countries. It also illustrates various approaches and strategies that drive such collaborations forward and eventually culminate in improving global health and local economies.

\section{Methods}

Literature reviews are known for their important summaries to the scientific field for addressing research issues by using explicit methods to find, select, assess and then analyze the related research studies included for the review.

\section{Search strategy and selection criteria}

Thisresearchisbasedonaliteraturereviewbetweentheyears 2000 and 2014 of documents retrieved from the databases Embase, PubMed/Medline, Global Health, and Google Scholar, and the websites of relevant international organizations, research institutions and philanthropic organizations. The following Mesh terms were used: "healthcare in BRICS", "healthcare challenges in BRICS", "essential medicine in BRICS", "essential drugs production in BRICS", "vaccines in BRICS", "health biotech in BRICS", "pharmaceutical collaboration in BRICS", "drugs manufacturing in BRICS", "health and pharmaceutical policies in BRICS", and "global health in BRICS".

\section{Data extraction}

After completing the search, the selected documents were summarized and categorized based on the topic and its implications. The results were synthesized using a framework of influence developed for the review from the health, economics and political science literature.

\section{Data collection and analysis}

In this review, the collected cases of collaboration in drug production discussed how to improve global health and local economies within the BRICS countries. During the collection process, numerous sources were used to conduct the search for such literature including search engines, specialized databases, and official websites of multinational firms involved in drug production in the BRICS region. The findings generated from all included studies formed the themes to critically analyze drug production in the BRICS bloc needed to improve global health and local BRICS economies. This study does not provide a detailed data quality.

\section{Results}

The initial search of databases and websites yielded 947 documents. Exclusion criteria narrowed the number of documents to 79 journal articles and 17 reports. A few studies provided sustained analysis of the BRICS' collective influence (17); the overwhelming tendency was to describe individual BRICS countries influence. Although influence was predominantly framed by the BRICS countries' material capability, there were examples of institutional and ideational influence - particularly from Brazil. Individual BRICS countries were primarily 'opportunity seekers' and region mobilisers but with potential to become 'issue leaders' and region organizers.

Production of drugs and vaccines in Brazil, Russia, India, China and South Africa (BRICS)

Currently, the BRICS countries possess the required infrastructure and the capacity to produce generics of many drugs for both their domestic markets and many Low- and Medium-Income Countries (LMICs). In addition, these countries are also capable to supply Active Pharmaceutical Ingredients (APIs) that are needed for manufacturing generics and on-patent drugs in LMICs (18). Similarly, other reports also state that the manufacturing of these ingredients is mainly occurring in the industrialized and developed world with an exception of a few emerging BRICS members such as Brazil, China, and India (19).

The influence of the BRICS alliance on the issue of "access to medicine" is significant during the prospective showdown between the BRICS alliance and the developed countries $(20,21)$. For example, the patent-based pharmaceutical manufacturers might as well still concentrate solely on the developed countries and will continue to be protected by 
vigorous intellectual property laws (22). Figure 1 illustrates how pharmaceuticals expenditure versus total health expenditure in the BRICS region during the period 1995-2010 where India leads pharmaceuticals expenditure compared to other BRICS. While Figure 2 depicts the total pharmaceutical expenditure per capita USD in BRICS and here Brazil leads other BRICS.

In Brazil, there has been a strategy to prioritize domestic production of essential medicines which represents a determinant factor to increase and sustain access. The majority of vaccines are manufactured locally and immunization rates reached very high levels and particularly with measles coverage reaching $99 \%$ (23).

The goal of the Russian strategy Pharmaceutical 2020 is to ensure that local drugs production would cover $50 \%$ of all generic drugs by 2017 and $50 \%$ of all innovative drugs by 2020. The implementation of this strategy was initiated by the Russian government as it secured 4 billion dollars in March 2011 and provided the local drug producers with preferential access to state reimbursement lists which encourage foreign companies to invest in Russia and become "localized" (24). This led to many cases of acquisitions and mergers which took place in Russia. For example, Sanofi-Aventis acquired controlling stake in the Russian manufacturer of insulin ZAO Bioton Vostok, hence became a local pharmaceutical producer; and Merck Sharp \& Dohme merged with ScheringPlough in Russia. In addition, more than 140 contracts have

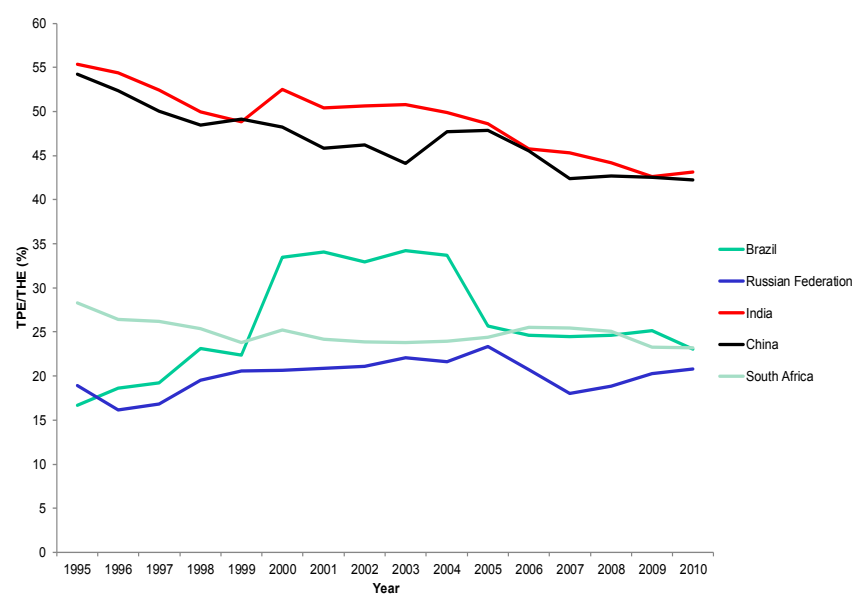

Figure 1. Pharmaceuticals expenditure versus total health expenditure in BRICS (Source NHA 1995-2010)

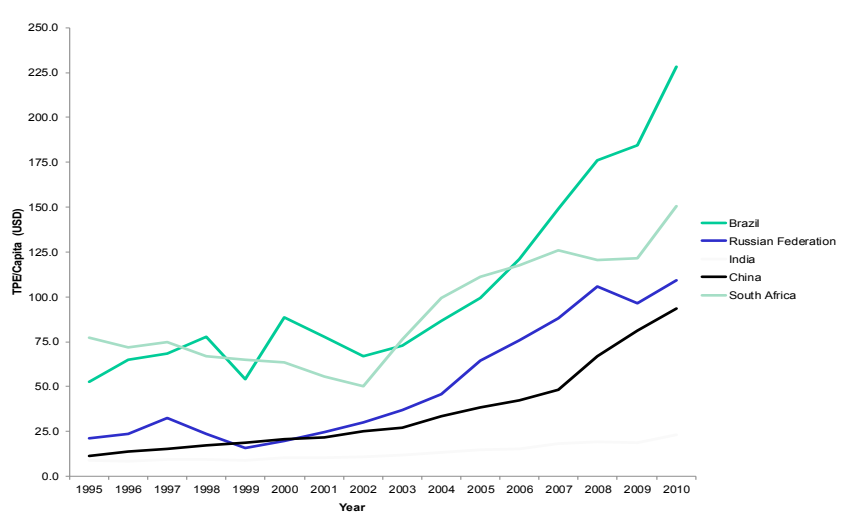

Figure 2. Total pharmaceutical expenditure per capita USD in BRICS (Source NHA 1995-2010) been approved such as the development of technologies for the manufacture of EDL, transfer of technology and knowhow for innovative drugs and pre-clinical and clinical drug research (25).

In order to promote local production of active pharmaceutical ingredients in South Africa, the Italian government accepted to fund a 9 million euros United Nations Industrial Development Organization (UNIDO)-coordinated project. This project helps to build up capacity for Good Manufacturing Practice (GMP)-compliant line of production to manufacture vaccines in the country (26).

Since many drugs are due to lose their patent protection in South Africa, the demand for essential medicines including generic antibiotics and over-the-counter drugs are expected to be on the rise. The number of local pharmaceutical firms is limited and most of them are focusing on production of chemicals and generic APIs and the last step synthesis is completed by the local subsidiaries of international pharmaceutical firms which are still dominating the industry $(27,28)$. The multinational pharmaceutical companies were reported to source one pint $5 \%$ of active ingredients, $36 \%$ of packing materials and $20 \%$ of excipients locally. The rest of inputs are usually imported from India and China, resulting in a relatively low value added in the entire pharmaceutical value chain (29).

Infrastructure of India's biotech and drugs production sectors and the private drug and vaccine manufacturers in India played major roles even in developing countries through increasing access to generic drugs.

Even though India showcased its low-cost production, however, the country has also clearly revolutionized health service delivery by crafting new approaches which have been adopted in various countries. This includes TB research center in Chennai that helped to develop the Directly Observed Treatment, Short-Course (DOTS). About 40 biomedical research centers such as the well-known Department of Biotechnology (DBT) are all funded through the government. The DBT has been pushing for innovating healthcare services in India including new vaccines for rotavirus.

The biotech companies not only kept investing in very lucrative $\mathrm{R} \& \mathrm{D}$ programs but also they also took advantage of the abundance of highly educated scientists, medical practitioners and IT professionals in India.

As of March 2012, India made a commitment to increase scientific collaboration with developing countries in a number of areas such as capacity building and knowledge transfer and adoption (30). For example, the Mumbai-based drug manufacturer Lupin Ltd. has established a partnership with Farmanguinhos and the Brazilian Ministry of Health $(\mathrm{MoH})$ to support the introduction of a four-in-one combination TB drug. This partnership states that Lupin will transfer the technology and the know-how to help Farmanguinhos launch it local manufacturing facility in Brazil (31).

Exports of India's pharmaceutical increased during the years 2006-7 in the USA and Europe and reached 57.8\%. However, those exports represent only $14.1 \%$ in Africa during the same period. For example, the sales from pharmaceutical products of the Indian pharmaceutical company Ipca Labs in Africa represent only $7.7 \%$, where Europe and the USA combined represent about $14.1 \%$ of the firm's total income (32).

In India, 72 WHO pre-qualified vaccines are produced by 8 local manufactures and between $60 \%$ and $80 \%$ of all vaccines 
procured by UN agencies are also manufactured locally. This has led to position India as the largest provider of a highquality and affordable vaccines for the developing world (33). These examples of collaboration between Indian firms and others from the BRICS and/or developing countries will reinforce and sustain the ability to manufacture and produce drugs cost-effectively and consequently improve global health. Drugs production in China by local and multinational firms The Swiss multinational pharmaceutical company Novatis completed acquisition of majority stakes in Zhejiang Tianyuan Bio-Pharmaceuticals. This will ultimately lead to increasing local production of vaccines in China (34). On the other hand, Chinese pharmaceutical companies are facing tough times in accessing American and European markets. The main factor related to this issue is due to the higher standards and requirements needed in obtaining official drug certifications from Western Food and Drug Administrations (FDAs).

As of August 2010, there were about 1,200 APIs manufacturers in China who are able to produce more than 1,500 categories of API. The country was ranked No.1 in the world in terms of production output of ingredients for penicillin, vitamins and antipyretics and analgesics (35).

The Chinese Pharmaceutical Shenzhen Hepalink is among the world the top largest producers of heparin sodium active pharmaceutical ingredients and produces mainly injectable grade heparin products (36). It is also one of the very few Chinese pharmaceutical firms to be both American FDA and European Union CEP certified.

Jiangsu Hengrui Medicine is the largest Chinese manufacturing base of antineoplastics and surgical medicine. It also provides drugs for a range of treatments including cardiovascular disease, endocrine ailments, antibiotics and for infusions during surgery. The firm manufactures and distributes pharmaceutical tablets, injections in the local market. Recently, it passed the inspections of the FDA and the European Union and hence was allowed to sell injection products in both the American and the European markets (37).

In 2005, drugs producers in Shandong manufactures averaged 20 essential medicine product licenses and around $60 \%$ of licensed products actually produced. In Gansu province, drugs producers averaged 41 licenses, however, only half of the products were actually produced. Therefore, the production output of essential medicines was not correlated with manufacturer sales volumes. In Shandong province, 8 out of 10 most frequently produced products were Western medicines. Meanwhile in Gansu, glucose injection was one of the most frequently manufactured products but the only Western medicine (10).

The German-based chemical and pharmaceutical company Bayer started producing drugs in China since 1997 and particularly focusing on Glucobay which represents China's best-selling diabetes medicine (38).

In 2011, the Chinese pharmaceutical Nanjing MeiRui Pharma Co, which is well-known for producing urology and allergy products, has been acquired by the British multinational pharmaceutical GlaxoSmithKline (GSK) (35). Besides the summer of 2013 scandal that connected Glaxo executives in bribery ordeal in China, GSK has been very active in signing strategic alliances with many Chinese pharmaceutical companies (35).
The European pharmaceutical company Nycomed (acquired by the Japanese pharmaceutical giant Takeda in 2011) became controlling shareholder of Guangdong Techpool Biopharma in 2010. Techpool focuses on manufacturing and marketing of biologic drugs derived from natural sources and various innovative protein drugs such as Iron Sucrose which is used for the treatment of iron deficiency anemia and patients who have chronic kidney disease (39).

This type of acquisition and mergers would even lead to not only decrease the overall drug production costs but also to expedite the drug innovation process in the future.

\section{Collaboration of Indian and Chinese biotech industries}

Given that China and India together account for about half of the poor people in the world, it is important to strike a balance or at least observe very closely the relationship between local producers and domestic drug consumers. There are many profitable biotech and pharmaceutical companies in China and India who are collaborating in providing health services to the poor. Cipla, Ranbaxy, and Hetero represent good examples where these companies are able to manufacture low-cost antimalarial and antiretroviral therapies in Africa. Shanghai United Cell Biotech successfully designed and produced the only tablet formulation of cholera vaccine with the collaboration with its Indian partner Pune, along with its 138-country global distribution network and relationships with United Nations Children's Fund (UNICEF), supplies one of every two doses of vaccine given in the entire world. Shantha Biotechnics located in Hyderabad reported to have been able to develop a cost-effective manufacturing process for hepatitis B vaccine (Shanvac-B) (40).

This huge potential of the Indian and Chinese biotech industries will help in shrinking the production costs of many drugs. In addition, collaboration between Indian and Chinese firms and others within the BRICS, developed/developing countries would even help poor countries to improve access to drugs to many disadvantaged populations.

\section{Discussion}

The BRICS economies are expected to exceed the G7 nations by 2050 . On the other hand, non-communicable diseases are poised to be Africa's largest killer. David Gold, attorney and principal of Global Health Strategies, argued that the BRICS are also expected to become key players in curing cancer by funding $\mathrm{R} \& \mathrm{D}$ in cancer and cancer drug development (41). This represents an opportunity where collaboration between the BRICS countries needs to be fostered within a framework of transparent rules, policies, and regulations.

The BRICS countries have successfully produced and enriched the world community with many vaccines. Table 1 below illustrates an example of vaccine production in the BRICS region (17).

In order to promote global health, international organizations would be more effective in pushing for an effective cooperation between BRICS and developing countries by advocating companies to pool their efforts when conducting research, marketing and developing medicines. Consequently, this initiative would help to supply drugs, vaccines and diagnostics to the poor and developing countries. This type of collaboration is a key driver in fulfilling drugs production shortages and 
Table 1. Vaccines produced in the BRICS countries

\begin{tabular}{|c|c|}
\hline Country & Vaccines produced \\
\hline Brazil & Influenza, pneumococcal conjugate, rabies, and rotavirus. \\
\hline Russia & $\begin{array}{l}\text { Brucellosis, diphtheria, tetanus, tularemia, varicella, } \\
\text { tularemia, mumps, and hepatitis for children and adults. }\end{array}$ \\
\hline India & $\begin{array}{l}\text { Pandemic influenza, seasonal influenza, typhoid } \\
\text { conjugate, and rubella. }\end{array}$ \\
\hline China & $\begin{array}{l}\text { Anthrax, hemorrhagic fever with renal syndrome, } \\
\text { hepatitis A, influenza } H 1 N 1 \text {, tick-borne encephalitis, } \\
\text { and tracheitis. }\end{array}$ \\
\hline South Africa & Hepatitis B. \\
\hline
\end{tabular}

BRICS= Brazil, Russia, India, China and South Africa

demands. To strengthen BRICS collaboration even through unreliable medicine supply systems (42), countries like China, India as well as Russia have the infrastructure and built up the capacity for producing cost-effective drugs (43).

Inter collaborations between the BRICS countries like Brazil, China and India need to set the pace and create more incentives to increase local production of drugs with LMICS countries. This initiative helps to increase access to medicines and contribute to economic and industrial development and to technological capacity and to achieve the Millennium Development Goal (MDG) targets for access to medicines (44-49). The know-how reservoir for local drugs production would not only serve to improve public health but also include pharmaceutical manufacturing and marketing, drug regulatory and registration issues, intellectual property, tax and tariff policies, and trade and commerce (50).

The BRICS countries have struggled for decades to be able to provide access to medicines as well as to satisfy public health requirements. The current reservoir of research and know how are adequate for these countries to plan and execute strategies to overcome existing and common health challenges. The BRICS countries need to joint efforts and explore cooperation initiatives and evidently joint funding opportunities that give rise to health/medical innovations that are above all accessible and reasonably priced for the disadvantaged and poor communities.

The main motivation of this work is to shed light on health biotechnology challenges in the BRICS region including the availability and production of drugs and vaccines and to report on the huge existing infrastructure and its impact on global health. This work also illustrates how the BRICS countries could collaborate on drugs production and be able to lower the cost of at least the essential medicines and ultimately improve access to drugs particularly in developing and poor countries. This work illustrates various opportunities of collaborations: inter BRICS, and between BRICS and developing countries. In addition, the contribution of this work is to showcase the status of existing infrastructures of this industry and opportunities to excel through collaboration. It also reveals various approaches and strategies that drive such collaborations forward and eventually culminate in improving global health and local economies.

\section{Conclusion}

Though small in number, the written output on BRICS influence in global health has increased significantly over the last few years. Whilst it may still be early days for newly-emerging economies influence in global health to have matured, this paper argues that there is scope to further develop the concept of influence in global health, but also to better understand the ontology of groups of countries such as BRICS. The BRICS countries have made a number of important commitments towards reforming global health, but if they are to be more than a memorable acronym they need to start putting those collective commitments into actions.

\section{Acknowledgements}

This work was supported by a Wharton grant funded by the Wharton Entrepreneurship and Family Business Research Centre at CERT in Abu Dhabi, UAE. I also would like to thank Dr. Abdul Ghaffar for giving me the opportunity to conduct research at the Alliance for Health Policy and Systems Research at the WHO headquarters in Geneva, Switzerland.

\section{Ethical issues}

Not applicable.

Competing interests

The author declare that he has no competing interests.

Author's contribution

$Z E$ is the single author of this manuscript

References

1. Harmer A, Xiao Y, Missoni E, Tediosi F. 'BRICS without straw'? A systematic literature review of newly emerging economies' influence in global health. Global Health 2013; 9: 15. doi: 10.1186/1744-8603-9-15

2. Harmer A, Folayinka D, Lesong C. The BRICS: what is their contribution to global health? A Global Village 2013; 9: 34-7.

3. Hau M, Scott J, Hulme D. Beyond the BRICs: alternative strategies of influence in the global politics of development. Eur J Dev Res 2012; 24: 187-204. doi: 10.1057/ejdr.2012.6

4. Petrie D, Tang KK. Relative health performance in BRICS over the past 20 years: the winners and losers. Bull World Health Organ 2014; 92: 396-404. doi: 10.2471/blt.13.132480

5. World Economic and Financial Surveys. World Economic Outlook Database [internet]. [cited 2013 November 5]. Available from: http://www.imf.org/external/pubs/ft/weo/2013/01/weodata/ index.aspx

6. Passarelli C, Pimenta C, Danishevskiy K, Singh S, Yan G, Kaufman J. Shifting paradigm: How the BRICS are reshaping global health and development, Global Health Strategies initiatives (GHSi) [internet]. [cited 2013 October 21]. Available from: http://www. eldis.org/go/display\&type=Document\&id=63081\#.UhXdGX-Yfo8

7. Harmer A, Buse K. The BRICS - a paradigm shift in global health? Contemporary Politics 2014; 20: 127-45. doi: 10.1080/13569775.2014.907988

8. Kirton J, Kulik J, Bracht C. Generating global health governance through BRICS summitry. Contemporary Politics 2014; 20: 14662. doi: 10.1080/13569775.2014.907990

9. Rao SG, Thomas D, Zachariah S, Kannan MS, Alvarez-Uria G. Comparison of essential drug list in a rural secondary care hospital in south India with Indian \& World Health Organization list 2011. Indian J Physiol Pharmacol 2012; 56: 375-81.

10. Chen W, Tang S, Sun J, Ross-Degnan D, Wagner AK. Availability and use of essential medicines in China: manufacturing, supply, and prescribing in Shandong and Gansu provinces. BMC Health Ser Res 2010; 10: 211. doi: 10.1186/1472-6963-10-211

11. Kaddar M, Milstien J, Schmitt S. Impact of BRICS' investment in vaccine development on the global vaccine market. Bull World Health Organ 2014; 92: 436-46. doi: 10.2471/blt.13.133298

12. Sáenz TW, Souza-Paula MC, Melon CM, Ray M, Thorsteinsdóttir 
H. Setting a southern course: Brazil's south-south collaboration in health biotech. In: Thorsteinsdóttir $\mathrm{H}$, editor. South-South Collaboration in Health Biotechnology: Growing Partnerships amongst Developing Countries. Ottawa: IDRC \& Academic Foundation; 2012. p. 99-121.

13. Chaturvedi S, Thorsteinsdóttir H. BRICS and south-south cooperation in medicine: Emerging trends in research and entrepreneurial collaborations [internet]. 2012. [cited 2013 July 10]. Available from: http://www.ris.org.in/images/RIS_images/ pdf/dp177_pap.pdf

14. Aly S, Madkour MA, Maram H, Adly N. Learning through collaborations: Egypt's south-south health biotechnology collaboration. In: Thorsteinsdóttir $\mathrm{H}$, editor. South-south collaboration in health biotechnology: Growing partnerships amongst developing countries. Ottawa: IDRC \& Academic Foundation; 2012. p. 153-72.

15. Access Campaign. MSF calls on BRICS countries to prioritize health and access to medical innovation [internet]. [cited 2014 August 18]. Available from: http://www.msfaccess.org/content/ msf-calls-brics-countries-prioritize-health-and-access-medicalinnovation

16. Liao, K. BRICS Nations Team to Strengthen Health Sector [internet]. [cited 2014 January 20]. Available from: http://www. borgenmagazine.com/brics-nations-team-strengthen-healthsector/

17. [No author listed]. Special theme: BRICS and the global health 2014. Bull World Health Organ 2014; 92: 385. doi: 10.2471/ BLT.14.000614

18. Timmermans K. Ensuring access to medicines in 2005 and beyond [internet]. [cited 2013 July 25]. Available from: http:// www.tansey.org.uk/docs/neg-health-intro.pdf

19. Rovira, J. Creating and promoting domestic drug manufacturing capacities: A solution for developing countries [internet]. 2006. [cited 2013 November 25]. Available from: https://www. unido.org/fileadmin/user_media/Services/PSD/BEP/Rovira_ Negotiating\%20Health 2006.PDF

20. Yu P. Access to medicines, BRICS alliances, and collective action. Am J Law Med 2008; 34: 345-94.

21. Laidi Z. BRICS: Sovereignty power and weakness. Int Politics 2012; 49: 614-32. doi: 10.1057/ip.2012.17

22. Yu PK. Access to medicines, BRICS alliances, and collective action. Am J Law Med 2008; 34: 345-94.

23. World Health Organization (WHO). Global Health Observatory (GHO) [internet]. [cited 2013 November 25]. Available from: http://www.who.int/gho/countries/bra/en/

24. Ross C. Building BRICs: Pharma's key emerging markets are becoming giants [internet]. [cited 2013 August 5]. Available from: http://www.pmlive.com/pharma_intelligence/building_ brics_pharmas_key_emerging_markets_are_becoming_ giants_483972

25. Ernst \& Young's 2012 attractiveness survey in Russia 2012 [internet]. [cited 2012 November 5]. Available from: http:// emergingmarkets.ey.com/wp-content/uploads/downloads/2012/09/ RAS_2012_2012_09.06_FINAL.pdf

26. United Nations Industrial Development Organization (UNIDO). Italy funds AIDS project in South Africa [internet]. [cited 2013 June 29]. Available from: http://www.manufacturingchemist. com/news/article_page/ltaly_funds_AIDS_project_in_South_ Africa/76154

27. MBendi. Pharmaceutical and Medicine Manufacturing in South Africa [internet]. [cited 2013 November 13]. Available from: http:// www.mbendi.com/indy/chem/phrm/af/sa/p0005.htm

28. Amuasi $\mathrm{JH}$. Technology transfer and local manufacturing of pharmaceuticals: The South African case [internet]. [cited 2013 December 9]. Available from: http://ictsd.org/downloads/2009/12/ amuasi-paper-edited.pdf

29. Maloney C, Segal N. The Growth Potential of the Pharmaceuticals Sector in South Africa. South Africa, Johannesburg: Genesis Analytics (Pty) Ltd; 2007.

30. Almeida C, Pires de Campos R, Buss P, Ferreira JR, Fonseca LE. Brazil's conception of south-south "structural cooperation" in health. Global Forum Update on Research for Health 2010; 4: 23-32.
31. Health Cooperation: Brazilian International Health Activities Bulletin [internet]. 2010. Available from: http://portal.saude.gov. br/portal/arquivos/pdf/Boletim_AISA_ING_alta.pdf

32. Chaudhuri $S$, Mackintosh $M$, Mujinja PG. Indian generics producers, access to essential medicines and local production in Africa: an argument with reference to Tanzania. European Journal of Development Research 2010; 22: 451-68. doi: 10.1057/ejdr.2010.27

33. Serruya SJ, Guimarães R, de Albuquerque IO, Morel CM. Research and innovation in Brazil: The institutional role of the ministry of health. Global Forum Update on Research for Health 2008; 5: 24-7.

34. Novaratis. Novartis completes acquisition of majority stake in Zhejiang Tianyuan expanding vaccines presence in China [internet]. 2014. [cited 2014 February 2]. Available from: http:// www.reuters.com/article/2011/03/22/idUS50620+22-Mar2011+HUG20110322

35. KPMG. China's Pharmaceutical Industry - Poised for the giant leap [internet]. [cited 2013 March 15]. Available from: http://www. kpmg.com/cn/en/issuesandinsights/articlespublications/pages/ china-pharmaceutical-201106.aspx

36. Wassener B. In China, Strong Debut for Supplier of Heparin. The New York Times [serial on the internet. 2010. Available from: http://www.nytimes.com/2010/05/07/business/global/07drug. $h$ tml? $r=0$

37. Jiangsu Hengrui [internet]. 2013. Available from: http://www.hrs. com.cn/english/

38. Kresge N. China's Thirst for New Diabetes Drugs Threatens Bayer's Lead [internet]. 2011. Available from: http://www. bloomberg.com/news/2011-11-20/china-s-thirst-for-new-diabetesdrugs-threatens-bayer-s-lead.html

39. Techpool [home page on the internet]. 2013. Available from: http://www.techpool.com.cn/index_en.html

40. Frew SE, Kettler HE, Singer PA. The Indian and Chinese Health Biotechnology Industries: Potential Champions Of Global Health? Health Aff (Millwood) 2008; 27: 1029-41. doi: 10.1377/ hlthaff.27.4.1029

41. Burki TK. BRICS nations tackle non-communicable diseases. Lancet Oncol 2012; 13: 451. doi: 10.1016/s1470-2045(12)70151-1

42. Elbeshbishi AN. TRIPS and public health: What should African countries do? ATPC Work in progress No. 49. Addis Ababa: Economic Commission for Africa; 2007.

43. Yusuf S, Nabeshima K, Perkins DH. China and India Reshape Global Industrial Geography. In: Winters A, Yusuf S, editors. Dancing with Giants-China, India, and the Global Economy. Washington and Singapore: The World Bank and the Institute of Policy Studies; 2007. p. 35-66.

44. World Health Organization (WHO). Public health, innovation and intellectual property rights. [internet]. 2006. Available from: http:// www.who.int/intellectualproperty/report/en/

45. Rao KD, Petrosyan V, Araujo E C, Mclntyre D. Progress towards universal health coverage in BRICS: translating economic growth into better health. Bull World Health Organ 2014; 92: 429-35. doi: 10.2471/blt.13.127951

46. Zandi L. Technology Transfer and Business Partnerships in BRICS: Development, Integration and Industrialization. Mediterranean Journal of Social Sciences 2014; 5: 284-93. doi: 10.5901/mjss.2014.v5n7p284

47. Littlejohns P. Banking on the BRICS for health? Lancet 2013; 381: 1158. doi: 10.1016/s0140-6736(13)60781-3

48. Shamik D. At last, some good news about the world economy. Management Today 2012; 7: 26-7.

49. Tseng CY. Technological Innovations in the BRIC Economies. Research Technology Management 2009; 52: 29-35.

50. Council on Health Research for Development (COHRED) and New Partnership for Africa's Development (NEPAD). Strengthening pharmaceutical innovation in Africa: Designing strategies for national pharmaceutical innovation: Choice for decision makers and countries [internet]. [cited 2013 July 21]. Available from: http://www.policycures.org/downloads/ COHRED-NEPAD_Strengthening_Pharmaceutical_Innovation AfricaREPORT.pdf

370 International Journal of Health Policy and Management, 2014, 3(7), 365-370 